\title{
Rapid and Highly Sensitive Determination of Melamine in Different Food Samples by Corona Discharge Ion Mobility Spectrometry after Dispersive Liquid-Liquid Microextraction
}

\author{
Roya Mirzajani* and Nahid Tavaf \\ Chemistry Department, Faculty of Science, Shahid Chamran University, Ahvaz, Iran
}

\begin{abstract}
In this work, for the first time, a highly sensitive method based on dispersive liquid-liquid microextraction coupled with positive corona discharge ion mobility spectrometry as a fast and inexpensive technique has been evaluated for the direct determination of melamine. The effective parameters influencing the microextraction efficiency, such as $\mathrm{pH}$, the properties of extraction and dispersion solvent were investigated. Under the optimum conditions, analytical parameters such as linearity, precision and limit of detection were evaluated. The calibration graph of melamine determination using the proposed method has two regions of linearity from 0.5 to $70 \mathrm{ng} \mathrm{mL}^{-1}$ and 70 to $1500 \mathrm{ng} \mathrm{mL}^{-1}$, the limit of detection and limit of quantification are 0.25 and $0.5 \mathrm{ng} \mathrm{mL}^{-1}$, respectively, and the relative standard deviation was less than $3 \%$ for all experiments. The proposed method was successfully applied for the determination of melamine in the milk, dairy products and egg yolk.
\end{abstract}

Keywords: melamine, ion mobility spectrometry, dispersive liquid-liquid microextraction

\section{Introduction}

Melamine (MEL), a nitrogen-containing heterocyclic organic base belonging to the triazine family (Figure 1), is a compound frequently applied in the production of laminates, plastics, coatings, commercial filters, adhesives, and dishware/kitchenware. ${ }^{1}$ Because of its high nitrogen level ( $66.6 \%$ by mass), MEL is illegally added to food such as milk, cookies and animal fodder to produce an inaccurately high readings in the measurement of protein content (which is based on total nitrogen content), resulting in some serious MEL residue related problems. The toxicity of MEL has become more well known since children were infected by an unprecedented epidemic of renal disease after consumption of MEL-tainted milk products. ${ }^{2,3}$ The toxicity of MEL alone is very low, and more than $90 \%$ of ingested MEL was shown to be eliminated within $24 \mathrm{~h}$ in an animal experiment. ${ }^{4}$ However, chronic exposure to MEL may cause cancer, damage the reproductive system, and irritate the eyes, skin, and respiratory tract. When MEL is absorbed into the bloodstream, it combines with uric acid, phosphate, or cyanuric acid. These are concentrated and interact with one another in the urine-filled renal microtubules, where

*e-mail: rmirzajani@scu.ac.ir they form large numbers of round, yellow crystals which block and damage the renal cells that line the tubes and cause the kidneys to malfunction. ${ }^{5,6}$

A safety limit for MEL ingestion has been officially set at $2.5 \mathrm{ppm}$ for adult food and $1.0 \mathrm{ppm}$ for infant formula by the US Food and Drug Administration. Ingestion of MEL at levels above the safety limit may cause kidney failure and even death, particularly for vulnerable individuals such as infants and young children. ${ }^{7}$ Therefore, it is prohibited to add MEL to food, especially dairy food, in most countries. Though, many detection methods for MEL have been developed. Currently, standard analytical techniques for determination of melamine are either low cost, low sensitivity techniques such as enzyme linked immunosorbent assays (ELISA) ${ }^{8}$ and high performance liquid chromatography with spectrophotometric diode array detector (HPLC-UV-DAD), ${ }^{9}$ or high sensitivity, high cost as chromatography-tandem mass spectrometry (GC-MS/MS) and high-performance liquid chromatography-tandem mass spectrometry (HPLC-MS/MS) ${ }^{10,11}$ hyphenated techniques. Hence, alternative methods include electrospray ionization mass spectrometry (ESI-MS), ${ }^{12}$ ion-pair liquid chromatography-tandem mass spectrometry, ${ }^{13}$ electromembrane-LPME followed by HPLC, ${ }^{14}$ gas chromatography/mass spectrometry, ${ }^{11}$ high-field asymmetric ion mobility spectrometry combined with solid-phase 
extraction, ${ }^{15}$ surface enhanced Raman spectroscopy, ${ }^{16}$ capillary zone electrophoresis-mass spectrum (CE-MS), ${ }^{17}$ electrochemical methods, ${ }^{18}$ surface plasmon resonance, ${ }^{19}$ and fluorescence immunosensor ${ }^{20}$ have been employed for the determination of melamine. However, some of these methods require tedious pretreatment of samples, have low levels of detection, consume large amounts of organic solvents, use reagents that are not commercially available, and use expensive equipment. Thus, it remains a great challenge to develop a simple and reliable method for the low cost, rapid, and sensitive determination of MEL adulteration. Despite remarkable improvements in the equipment used for the separation and analysis of chemical compounds, sample preparation remains a very important step in the development and application of methods for the analysis of chemicals. Moreover, in recent years, many sample pretreatment steps have been directed toward the fast development of simplification and miniaturization. Microextraction techniques are fast, simple, inexpensive, environmentally friendly, and compatible with many analytical instruments. ${ }^{21}$ Since dispersive liquid-liquid microextraction (DLLME) was proposed by Assadi and co-workers in $2006,,^{22}$ this method has quickly gained popularity because of its significant advantages including less solvent usage, shorter extraction times, and a higher enrichment ratio. Briefly, this technique combines a nonpolar solvent (extraction solvent) with a polar one (dispersive solvent), in such a way as to ensure the efficient dispersal of the nonpolar solvent within the aqueous bulk, thereby improving the efficiency of the microextraction technique. ${ }^{23}$ When a few microliters of extractant and disperser are rapidly injected into the aqueous sample, a cloudy emulsion forms. In the emulsion, innumerable small droplets of extractant with large surface area are dispersed into the entire aqueous sample, quickly achieving equilibrium and resulting in a short extraction time. Phase separation is easily achieved by centrifugation, and then a sedimentary phase is used with the appropriate analytical method. ${ }^{24}$ Compared with other miniaturized techniques in which the analytes are extracted on a solid phase, e.g., solid-phase microextraction (SPME) and stir bar sorptive extraction (SBSE), the main advantages of DLLME are its rapidity, low cost, and lack of memory effects..$^{25}$

These benefits are causing scientists to apply DLLME in the analysis of various compounds in different environmental and foodstuff samples. ${ }^{26}$ DLLME is a highly versatile sample-preparation method, not only because it can be used for practically all classes of analytes, but also because it is compatible, directly or after solvent replacement, with a wide range of final detection techniques. DLLME can be combined with techniques such as ultraviolet-visible light<smiles>Nc1nc(N)nc(N)n1</smiles>

Figure 1. Structure of melamine (molecular formula: $\mathrm{C}_{3} \mathrm{H}_{6} \mathrm{~N}_{6}$ ).

(UV-Vis) spectrophotometry, gas chromatography and high performance liquid chromatography. ${ }^{27-30}$

Recently, ion mobility spectrometry (IMS) has become a serious alternative to the traditional methods used for detection purposes. IMS is an analytical technique based on the gas-phase separation of ionized compounds under an electric field at ambient pressure by their mobility in the drift gas. ${ }^{26}$ This technique has been widely adopted for the detection of trace amounts of illegal drugs, explosives, pharmaceuticals, and environmental pollutants. ${ }^{31}$ IMS rapidly and sensitively detects compounds based on differences in structural shape, size, and mass-to-charge $(\mathrm{m} / \mathrm{z})$ ratio and can readily be adapted to include new detection targets. ${ }^{32}$ Alternatively, IMS can provide resolving power similar to chromatography as a separation technique and could be developed to provide separation capabilities at lower cost and with greater ease of operation for potential use in typical clinical settings.

Various atmospheric pressure ionization sources including ${ }^{63} \mathrm{Ni}$ radioactive source, UV ionization, and corona discharge $(\mathrm{CD})$ have been used for ionization in IMS. CD is nonradioactive which is capable of producing a current one order of magnitude higher than ${ }^{63} \mathrm{Ni}$ and it has successfully been used to detect many compounds. ${ }^{33,34}$

This paper reports a new method developed for the direct determination of MEL in milk, dairy products and egg yolk sample using CD-IMS combined with DLLME. In this work, for the first time a combination of DLLME and CD-IMS (DLLME-CD-IMS) was used for the determination of MEL in food samples without other pre-separation treatment. Some parameters affecting the extraction efficiency, such as type and volume of extraction solvent, type and volume of dispersive solvent, salt effect and $\mathrm{pH}$, were studied. The main goal of this article is to propose a simple, cheap, fast, relatively green, and highly sensitive method for the determination of MEL in various real samples.

\section{Experimental}

Ion mobility spectrometer and instrumentation

The ion mobility spectrometer (Isfahan, TOF Tech. Pars) used in this study was designed and constructed at 
Isfahan University of Technology, Iran. ${ }^{33,34}$ The main parts of the instrument include an IMS cell which was housed in a thermostatted oven in which the temperature was controlled to within $\pm 1{ }^{\circ} \mathrm{C}$ and equipped with a $\mathrm{CD}$ ionization source, two high voltage power supplies, a shutter grid, a pulse generator, an analog to digital converter, and a computer to record spectra. The ion mobility spectrometer consisted of two regions; an ionization region (including the $\mathrm{CD}$ needle region) and a drift region (11 cm in length). In all the experiments, the needle potential was kept constant to create a stable and steady corona, experiments were conducted in positive ion mode, and nitrogen was used as the drift and carrier gases. The flow rates of the drift and the carrier gas were 400 and $1,000 \mathrm{~mL} \mathrm{~min}^{-1}$, respectively, also a voltage of $7 \mathrm{kV}$ was applied over the entire cell to create a drift field of $437.5 \mathrm{~V} \mathrm{~cm}^{-1}$. When the ions experience the drift field, they begin moving toward the detector, which is a simple Faraday cup. After the sample was evaporated in the injection port of the IMS, the analyte vapor was passed through the ionization chamber where ions are formed and focused to the shutter grid. The shutter grid was made of two series of parallel wires that are biased to a potential to create an orthogonal field relative to the drift field. This blocked the passage of ions to the drift tube. The shutter opening time was set at $200 \mu$ s, allowing the ions to pass at short pulses towards the separation chamber. A flow of nitrogen at $400 \mathrm{~mL} \mathrm{~min}^{-1}$ in the opposite direction to the drifting ions was employed as the drift gas in order to prevent non-ionized impurities from entering the separation chamber. A gas outlet line made the gaseous streams exit the instrument. All parts of the IMS that were in contact with the analytes were constructed from inert materials.

All IMS spectra were obtained by data acquisition software and each IMS spectrum was the average of 50 individual spectra. A Metrohm 632 (Switzerland) $\mathrm{pH}$-meter was used to measure $\mathrm{pH}$ with a combined glass electrode. A model BHG HERMLE centrifuge (Germany) was used for the phase separation.

\section{HPLC system}

In this study, the HPLC system was a Knauer (Berlin, Zehlendarf, Germany) and consisted of a K-1001 pump and a k-2501 UV detector. Cellulose acetate and polytetrafluoroethylene (PTFE) filters (SCA grade, $0.45 \mu \mathrm{m}, 25 \mathrm{~mm}, \mathrm{CHMLAB}$, Barcelona, Spain) were applied for the filtration of aqueous and organic solvents prior used. The column used was Eurosphere $\left(\mathrm{C}_{18}\right.$, $250 \mathrm{~mm} \mu 4.6 \mathrm{~mm}$ ) with mixture solution of methanol and water $(50: 50, v / v)$, throughout as the mobile phase and a $20 \mu \mathrm{L}$ injection loop. Flow rate of mobile phase was
$0.8 \mathrm{~mL} \mathrm{~min}^{-1}$. The temperature of the column oven was adjusted to a constant temperature at $25{ }^{\circ} \mathrm{C}$. Under these conditions, retention times for melamine chromatographic peak was $6 \mathrm{~min}$. Detection wavelength was set to $280 \mathrm{~nm}$ for determination of melamine.

\section{Reagents and standards}

All chemicals were of analytical grade and double distilled water was used throughout. A stock solution of melamine $\left(200 \mathrm{mg} \mathrm{mL}^{-1}\right)$ was prepared by dissolving of $0.02 \mathrm{~g}$ pure compound (Merck, Darmstadt, Germany) in water and diluting to $100 \mathrm{~mL}$ in a volumetric flask. Working standard solutions were obtained daily by successive dilutions of this stock solution. All organic solvents (acetonitrile, methanol, acetone, chloroform and carbon tetrachloride) were HPLC grade and purchased from Merck (Darmstadt, Germany). Doubly distilled water was used in all experiments. Sodium chloride, hydrochloric acid, sodium hydroxide and phosphoric acid were analytical reagent grade (Merck).

\section{Extraction procedure}

For DLLME under optimum conditions, a portion of the sample solution $(10 \mathrm{~mL})$ containing MEL was placed into a conical centrifugal tube. Then, a mixture of solvents $(1.0 \mathrm{~mL})$, containing acetonitrile as the disperser solvent and dichloromethane as the extraction solvent, was rapidly injected using a $1 \mathrm{~mL}$ glass syringe (Gastight, Hamilton). After manual shaking, a cloudy solution was formed in the test tube after $6 \mathrm{~min}$, and separation of the phases was then achieved by centrifugation of the mixture at $6000 \mathrm{rpm}$ for $3 \mathrm{~min}$. After centrifugation, the extraction solvent that had settled at the bottom of the conical tube (volume recovered $150 \pm 10 \mu \mathrm{L}$ ) was removed using a $500 \mu \mathrm{L}$ syringe, evaporated to near dryness using a gentle stream of $\mathrm{N}_{2}$ and reconstituted with of methanol $(15 \mu \mathrm{L})$. Finally, an aliquot $(5 \mu \mathrm{L})$ of the reconstituted solution was injected into the IMS injection port with a microsyringe for further analysis.

\section{Real sample preparation}

\section{Egg yolk}

Egg yolk samples were manually separated from the albumen by placing them on absorbing paper and then homogenized by a food processor. Yolk $(0.1 \mathrm{~g})$ was weighted, added to doubly distilled water $(10 \mathrm{~mL})$ and shaken for $1 \mathrm{~min}$. The yolk suspension was then centrifuged at $2000 \mathrm{rpm}$ for $2 \mathrm{~min}$. An aliquot $(100 \mu \mathrm{L})$ of the upper aqueous phase was spiked with a standard solution of 
MEL, treated with acetonitrile $(0.4 \mathrm{~mL})$, and centrifuged at $1000 \mathrm{rpm}$ for $1 \mathrm{~min}$. The upper aqueous layer was then transferred to another test tube for the extraction of MEL according to the proposed DLLME-CD-IMS method. ${ }^{35}$

Milk

An aliquot $(1 \mathrm{~mL})$ of a milk sample that had been previously centrifuged at $2000 \mathrm{rpm}$ for $10 \mathrm{~min}$ was treated with acetonitrile $(0.4 \mathrm{~mL})$ and centrifuged at $1000 \mathrm{rpm}$ for $1 \mathrm{~min}$. The upper aqueous layer was transferred to another test tube for the extraction of MEL according to the procedure described in the Extraction procedure section. ${ }^{35}$

\section{Milk powder sample}

Powdered milk (3 grams) was dissolved in methanol $(60 \mathrm{~mL})$ via ultrasonic bath. Dilute acetic acid $(1 \mathrm{~mL}, 3 \%$, $\mathrm{v} / \mathrm{v}$ ) was then added, and the solution stored at $4{ }^{\circ} \mathrm{C}$ for at least $30 \mathrm{~min}$. After $15 \mathrm{~min}$ of centrifugation $(\mathrm{rpm}=60000)$, the solution was filtered through a $0.2 \mu \mathrm{m}$ filter, and the supernatant was transferred to a $10 \mathrm{~mL}$ volumetric flask for the extraction of MEL according to the proposed DLLME-CD-IMS method. ${ }^{36}$

\section{Cheese and yogurt sample}

A portion of sample $(2.0 \mathrm{~g})$ was added to a $50 \mathrm{~mL}$ centrifuge tube. To this was added $5 \%$ trichloroacetic acid in water $(15 \mathrm{~mL})$ and acetonitrile $(5 \mathrm{~mL})$, and the tube was then capped, sonicated for $10 \mathrm{~min}$, placed on a vertical shaker for $10 \mathrm{~min}$, and centrifuged for $10 \mathrm{~min}$ at $4000 \mathrm{rpm}$. A filter paper was then wetted with $5 \%$ trichloroacetic acid in water, and the supernatant filtered through it into a $25.0 \mathrm{~mL}$ volumetric flask. The volume of liquid in the flask was brought up to $25 \mathrm{~mL}$ by adding $5 \%$ trichloroacetic acid in water. ${ }^{16} \mathrm{An}$ aliquot $(5.0 \mathrm{~mL})$ of the extract was transferred into a glass tube, to which was then added purified water $(5.0 \mathrm{~mL})$. This mixture was vortexed and then used for the extraction of MEL according to the procedure described in the Extraction procedure section. ${ }^{36}$

\section{Calculation of enrichment factor (EF) and extraction recovery $(\mathrm{ER})$}

Enrichment factor $(\mathrm{EF})$ was calculated using the ratio of the analyte concentration in the sedimented phase $\left(\mathrm{C}_{\mathrm{sed}}\right)$ to the initial concentration of analyte $\left(\mathrm{C}_{0}\right)$ within the sample: ${ }^{37}$

$\mathrm{EF}=\frac{\mathrm{C}_{\text {sed }}}{\mathrm{C}_{0}}$

The extraction recovery (ER) was calculated according to:
$\mathrm{ER}=\left(\frac{\mathrm{C}_{\text {sed }} \times \mathrm{V}_{\text {sed }}}{\mathrm{C}_{0} \times \mathrm{V}_{\mathrm{aq}}}\right) \times 100$

where $\mathrm{V}_{\mathrm{aq}}$ is the volume of aqueous phase and $\mathrm{V}$ is the final volume of the sedimented organic drop.

\section{Results and Discussion}

The ion mobility spectrum of analyte was obtained after direct injection of the standard sample solution into the IMS system. A standard solution of $40 \mathrm{ng} \mathrm{L}^{-1}$ of MEL in methanol was injected into the injection port of the CD-IMS. The ion mobility spectrum of melamine in comparison with background spectrum is illustrated in Figure S1. Its spectrum shows only one peak at $7.8 \mathrm{~ms}$, which is much longer than that of the reactant ion peak $\left(\mathrm{NH}_{4}^{+}\right)$. In order to obtain the best sensitivity, the effective instrumental parameters of IMS, including corona and drift voltages, injection port and oven (cell) temperatures, carrier and drift gas flow rates, and pulse width, must be investigated. The operating conditions are presented in Table 1.

Table1. The optimized IMS experimental conditions for melamine detection by DLLME-CD-IMS

\begin{tabular}{lc}
\hline Parameter & Setting \\
\hline Length of drift tube / cm & 11 \\
Drift field / $\left(\mathrm{V} \mathrm{cm}^{-1}\right)$ & 700 \\
Corona voltage / & 2250 \\
Flow of drift gas $\left(\mathrm{N}_{2}\right) /\left(\mathrm{mL} \mathrm{min}^{-1}\right)$ & 1000 \\
Flow of carrier gas $\left(\mathrm{N}_{2}\right) /\left(\mathrm{mL} \mathrm{min}^{-1}\right)$ & 400 \\
Doping gas & $\mathrm{NH}_{3}$ \\
Flow rate of doping gas / $\left(\mathrm{mL} \mathrm{h}^{-1}\right)$ & 0.0 \\
Injection port temperature / ${ }^{\circ} \mathrm{C}$ & 230 \\
IMS cell temperature / ${ }^{\circ} \mathrm{C}$ & 200 \\
Pressure / Torr & 630 \\
Typical shutter grid pulse width / $\mu \mathrm{s}$ & 200 \\
\hline
\end{tabular}

Of these parameters, the temperatures of injection and the oven were of greatest significance. The optimum injection temperature varied according to the structure of the compound, its stability, and melting point. The oven temperature was optimized to obtain the highest signal intensity and also to prevent solvent condensation and memory effect in the IMS cell. The effect of the injection port temperature on the determination of MEL was studied in the range of $160-230^{\circ} \mathrm{C}$. Increasing the temperature to $215^{\circ} \mathrm{C}$ led to an increase in the signal intensity, while at higher values it was constant. Under the optimum injection port temperature, the oven temperature also varied within 
the range of $160-200{ }^{\circ} \mathrm{C}$. It was found that in the range of $180-200{ }^{\circ} \mathrm{C}$, the signal intensity was at its highest value. Therefore, 220 and $200{ }^{\circ} \mathrm{C}$ were selected as the best values for the injection and oven temperatures of IMS, respectively. In IMS, ion drift times are often reported as reduced mobility constants, and reduced mobility $\left(\mathrm{K}_{0}, \mathrm{~cm}^{2} \mathrm{~V}^{-1} \mathrm{~s}^{-1}\right)$ is often used instead of drift time $\left(t_{d}\right)$ for identification purposes. In ambient-pressure IMS measurements, the reduced mobility of an ion under normalized temperature and pressure conditions is given as: $:^{38}$

$K=\frac{v}{E}=\frac{l_{d}}{E \times t_{d}}$

where $v$ is the velocity of ions, $l_{d}$ is the drift length, $K$ is the mobility, $\mathrm{E}$ is the electrostatic field in the drift region, and $\mathrm{t}_{\mathrm{d}}$ is the drift time. Mobilities are usually normalized to $273 \mathrm{~K}$ and 760 Torr, and are reported as reduced mobilities, $\mathrm{K}_{0}: 39$

$\mathrm{K}_{0}=\mathrm{K} \frac{273}{\mathrm{~T}} \times \frac{\mathrm{P}}{760}$

where $\mathrm{P}$ is the pressure (Torr) and $\mathrm{T}$ is the temperature (Kelvin). In this study, we used $\mathrm{NH}_{4}{ }^{+}$as the external standard to calibrate the reduced mobility scale. By doing so, we calculated a reduced mobility value of $1.83 \mathrm{~cm}^{2} \mathrm{~V}^{-1} \mathrm{~s}^{-1}$ for MEL. In this study, the effects of several important parameters influencing the extraction efficiency of MEL, including dispersion and extraction solvent, $\mathrm{pH}$, salt effect, extraction time and centrifugation time, were investigated.

\section{Effect of type and volume of the dispersion solvent}

In DLLME, the dispersive solvent plays a critical role in ensuring that the extractant solvent disperses as fine, uniform droplets into the sample solution. ${ }^{26}$ In the presence of the dispersive solvent, a water/dispersive/extractant solvent emulsion system was formed, which could increase the contact surface of the extractant solvent with the analytes, thereby improving the extraction efficiency. In this experiment, methanol, acetone, and acetonitrile were investigated as dispersive solvents. According to the results in Figure 2, the highest extraction efficiency was obtained in the case of acetonitrile as the dispersive solvent, and this solvent was used thereafter.

The effect of the volume of acetonitrile on the extraction efficiency was also examined. To obtain the optimized volume of acetonitrile, various experiments were performed using different volumes of acetonitrile (200, 300, 400, 500 and $600 \mu \mathrm{L}$ ). In light of the results obtained, $400 \mu \mathrm{L}$ of acetonitrile was chosen as the optimum volume (Figure 3a).

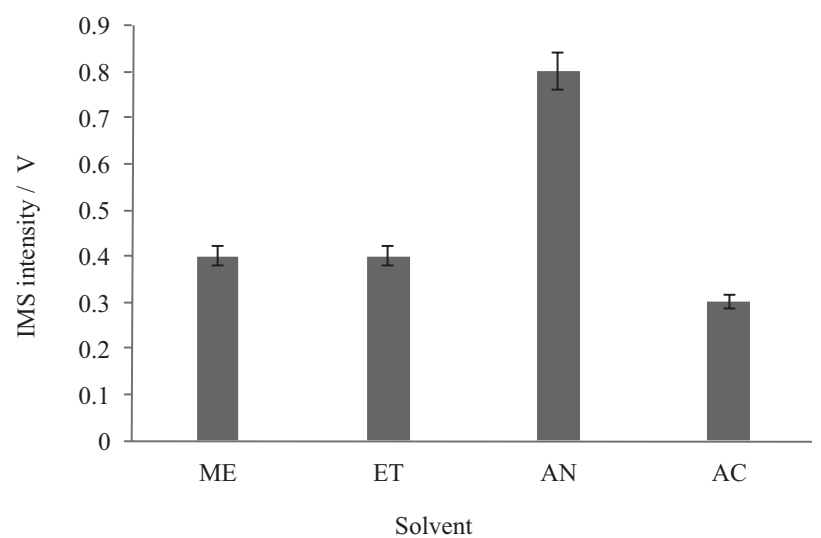

Figure 2. Effect of different kind of dispersive solvent on the extraction efficiency (ME: methanol; ET: ethanol; AN: acetonitrile; AC: acetone); Conditions: sample volume: $10 \mathrm{~mL}$ containing $1 \mu \mathrm{g} \mathrm{mL}^{-1}$ of melamine; extraction solvent volume: $350 \mu \mathrm{L}$; extraction time: $2 \mathrm{~min}$; centrifugation time: 4 min.

\section{Effect of type and volume of the extraction solvent}

In DLLME-IMS, the selection of suitable organic solvents is based on the requirement of the solvent's extraction capability for target compounds and its IMS behavior. It should have a higher density than water, be capable of extracting the compounds of interest, and have low solubility in water. MEL is only slightly soluble in water, but they are easily soluble in organic solvents. Several extracting solvents, including chloroform, dichloromethane, and carbon tetrachloride, were investigated. The experiments were performed by using $350 \mu \mathrm{L}$ of each extracting solvent and $400 \mu \mathrm{L}$ of acetonitrile (as the dispersion solvent). Results showed that the maximum extraction recovery was obtained by using dichloromethane. In order to examine the effect of the extraction solvent volume, solutions containing different volume of dichloromethane (300, 400, 500, 600, 700 and $800 \mu \mathrm{L}$ ) were subjected to the same DLLME procedure. In the following studies, the optimum volume of $600 \mu \mathrm{L}$ was selected for the extraction solvent volume (Figure 3b).

\section{Effect of $\mathrm{pH}$}

The $\mathrm{pH}$ of the sample solution is another important parameter that may have an influence on the extraction performance. The effects of $\mathrm{pH}$ on DLLME are important and depend on the acidity or basicity of the compounds. The analytes can be extracted by an extraction solvent when they are in the non-ionized form. The effect of the sample $\mathrm{pH}$ in a range of 3-12 on the extraction of the MEL was also investigated (Figure 4). MEL is a weak alkaline compound that can hydrolyze in strong acid or alkali solutions, and the $\mathrm{pH}$ of the solution influences the form of MEL molecules 


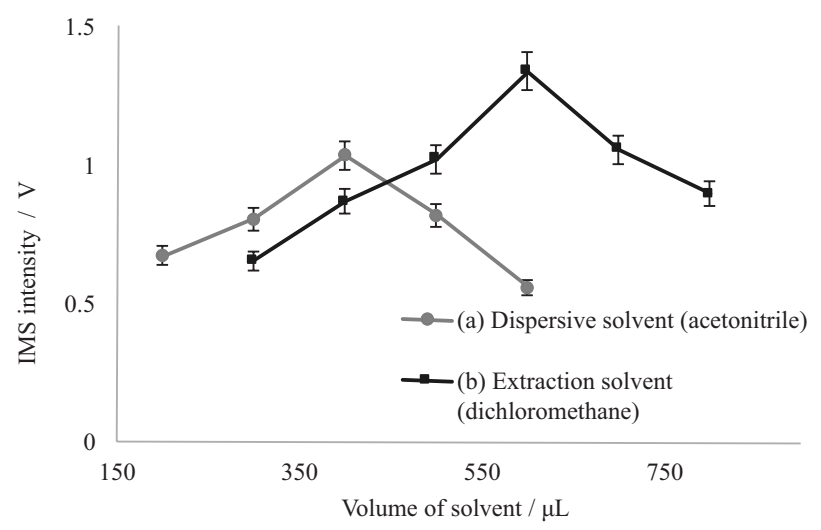

Figure 3. (a) Effect of dispersive solvent volume (acetonitrile) on the extraction efficiency of melamine, with $500 \mu \mathrm{L}$ dichloromethane as extraction solvent. (b) Effect of dichloromethane volume as extraction solvent on the extraction efficiency of melamine (dispersion solvent volume: $400 \mu \mathrm{L}$ ), conditions: sample volume: $10 \mathrm{~mL}$ containing $1 \mu \mathrm{g} \mathrm{mL}$ of melamine; extraction time: $2 \mathrm{~min}$; centrifugation time: $4 \mathrm{~min}$.

in the aqua phase. MEL extraction can be carried out in neutral, acidic and alkali conditions, but acidic and neutral extraction conditions are most common for food. Melamine is a weak base with a $\mathrm{pK}_{\mathrm{a}}$ of $5.05,{ }^{40}$ and is readily protonated in aqueous solution at $\mathrm{pH}$ lower than 5.0 which caused a low partition from the water sample into acetonitrile and then organic phase. Therefore, the extraction efficiency and the IMS signal for the extracted samples decreases in acidic conditions and there were no obvious differences in the extraction recoveries of the MEL when the $\mathrm{pH}$ of the sample solutions was varied from 4 to 12 .

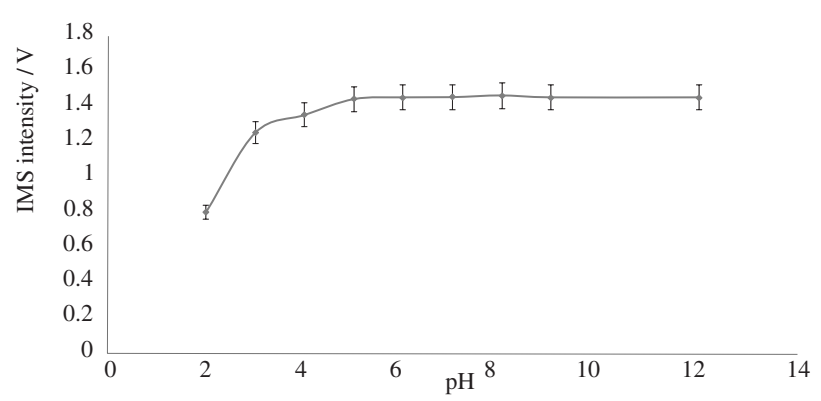

Figure 4. Effect of $\mathrm{pH}$ on the extraction efficiency, conditions: sample volume: $10 \mathrm{~mL}$ containing $1 \mu \mathrm{g} \mathrm{mL}^{-1}$ of melamine; extraction solvent volume: $600 \mu \mathrm{L}$; dispersion solvent volume: $400 \mu \mathrm{L}$; extraction time: $2 \mathrm{~min}$; centrifugation time: $4 \mathrm{~min}$.

It was found that a sample $\mathrm{pH}$ above 4 does not have a significant effect on the extraction efficiency of MEL in the $\mathrm{pH}$ range investigated. According to our obtained results, protonation and hydrolysis of MEL is at its minimum at $\mathrm{pH}$ values higher than 4 , and the analyte is in its molecular form. On the basis of these results, $\mathrm{pH}$ values in the range 4-8 can be used for further analysis. It should be noted that the $\mathrm{pH}$ of all the samples used in this study was within the range 4-6, and hence $\mathrm{pH}$ adjustment was not required.

\section{Effect of ionic strength}

To investigate the influence of ionic strength on the performance of DLLME, various experiments were performed by adding different amounts of sodium chloride $(\mathrm{NaCl})(2-20 \%, \mathrm{~m} / \mathrm{v})$. The addition of salt to the sample solution can increase the ionic strength of the water, thus reducing the solubility of analytes in the sample solution. According to the results, the extraction efficiencies of the analytes showed an increase when the $\mathrm{NaCl}$ concentration increased from 0 to $10 \%$. However, the extraction efficiencies decreased with further increases in salt concentration. Many researchers investigating the "salting-out" effect have also reported similar results, ${ }^{26,27}$ i.e., that the solubility of the analytes in the sample solution decreased due to an increase in ionic strength, thus promoting the extraction efficiency. On the other hand, there is a possibility that these polar target analyte molecules participated in electrostatic interactions with the salt ions in the solution and thus caused the polar molecules to precipitate. ${ }^{28}$ This process could block the analytes from being extracted into the extractant. Thus, the initial increase of salt concentration could improve the extraction efficiency, but worsen with a further increase of salt concentration. The results in Figure 5 demonstrate that the IMS signal slowly increased with the addition of $\mathrm{NaCl}$ to a concentration of up to $10 \%(\mathrm{~m} / \mathrm{v})$ and then decreased when further $\mathrm{NaCl}$ was added. Hence, a $\mathrm{NaCl}$ concentration of $10 \%(\mathrm{~m} / \mathrm{v})$ was chosen for further experiments.

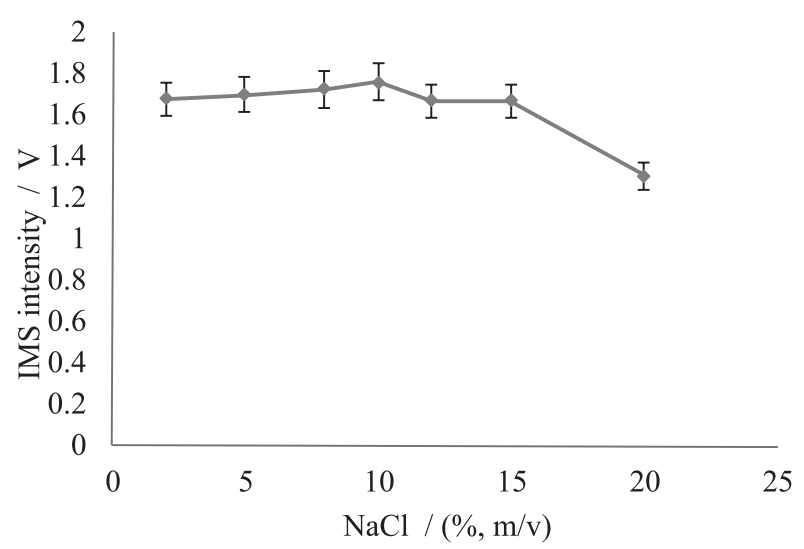

Figure 5. Effect of $\mathrm{NaCl}$ on the extraction efficiency. Conditions: sample volume: $10 \mathrm{~mL}$ containing $1 \mu \mathrm{g} \mathrm{mL}-1$ of melamine; extraction solvent volume: $600 \mu \mathrm{L}$; dispersion solvent volume: $400 \mu \mathrm{L}$; extraction time: $2 \mathrm{~min}$; centrifugation time: 4 min.

\section{Effect of extraction time}

In DLLME, extraction after injecting the extraction solvent is achieved very quickly as the surface area between the sample and organic solvent is extremely large due to the use of a disperser. As in most extraction procedures, 
the extraction time is one of the most important factors in DLLME because the mass-transfer is a time-dependent process and sufficient time is needed to permit partitioning of the analyte between the sample solution and organic phase. The extraction time is defined as the time interval between the addition of the mixture of dispersive solvent (acetonitrile) and extraction solvent (dichloromethane) and the beginning of centrifugation. The effect of extraction time was studied over the time range between 2 and $15 \mathrm{~min}$. From the corresponding results (data not shown), it was observed that the peak area generally increased with addition of extraction time up to $6 \mathrm{~min}$ and then remained rather constant, hence, in the following studies, 6 min was chosen as the optimum extraction time.

\section{Effect of centrifugation time}

The effect of centrifugation time was studied in the range of 2-15 min at $6000 \mathrm{rpm}$ (Figure 6). In DLLME, after the extractant mixture was injected into the sample solution, the mass transfer equilibrium of the analyte was achieved in a short period because of the large contact surface between the tiny drops of extractant solvent and the sample. Thus, centrifugation was utilized to help separate the two phases. At $8 \mathrm{~min}$, the extraction efficiency became constant, indicating the complete transfer of the organic phase. A very short centrifugation time cannot insure satisfactory phase separation, and a longer centrifugation time causes a negligible effect on the extraction efficiency. Therefore, the optimum centrifugation time was determined as $8 \mathrm{~min}$, and a centrifugation time of $8 \mathrm{~min}(5000 \mathrm{rpm})$ was chosen to ensure that the transfer of droplet to bottom of a centrifuge tube.

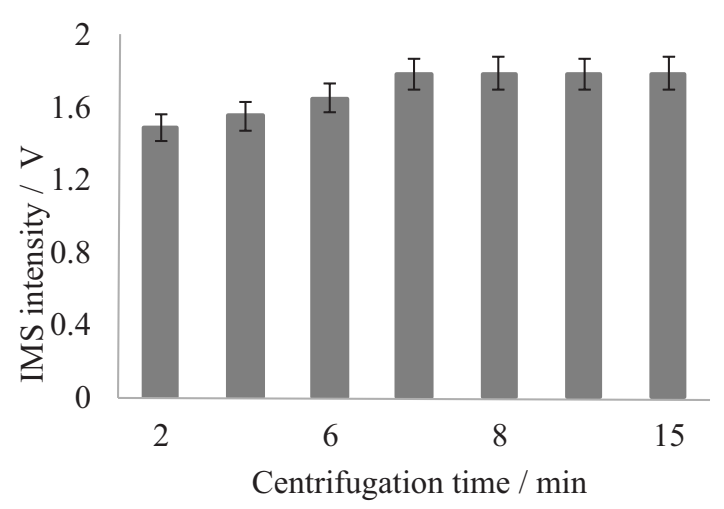

Figure 6. Effect of centrifugation time on extraction efficiency. Conditions: sample volume: $10 \mathrm{~mL}$ containing $1 \mu \mathrm{g} \mathrm{mL}^{-1}$ of melamine; concentration of salt: $10 \%(\mathrm{~m} / \mathrm{v})$; extraction time: $6 \mathrm{~min}$; extraction solvent volume: $600 \mu \mathrm{L}$; dispersion solvent volume: $400 \mu \mathrm{L}$.

\section{Figures of merit for the proposed method}

Important figures of merit such as limit of detection and quantification, linear range, reproducibility, recovery, and enrichment factors to evaluate the performance of the methodology were obtained.

Two linear relationships between the IMS analytical signal and the MEL concentration after the preconcentration procedure in the samples were verified in the 0.5-70 and $70-1500 \mathrm{ng} \mathrm{mL}^{-1}$ ranges. The first was given as $\mathrm{A}=0.0152 \mathrm{C}+0.2801$, with a correlation coefficient of 0.9978 , and the second was given as $\mathrm{A}=0.0006 \mathrm{C}+1.289$, with a correlation coefficient of 0.9979 , where $\mathrm{A}$ is the peak intensity for MEL in the rich phase, and $\mathrm{C}$ is the concentration of MEL in the sample solution in $\mathrm{ng} \mathrm{mL}^{-1}$. The limit of detection (LOD, S/N = 3) and the limit of quantification (LOQ, $\mathrm{S} / \mathrm{N}=10$ ) of this method were calculated as 0.25 and $0.5 \mathrm{ng} \mathrm{mL} \mathrm{m}^{-1}$, respectively. Reproducibility was calculated as the percentage of relative standard deviation (RSD\%). ${ }^{41}$ RSD\% values were assessed from seven identical and independent experiments. An acceptable precision was obtained with RSD values below 3.9 and $2.7 \%(\mathrm{n}=10)$ at the spiked concentration levels of 5 and $40 \mathrm{ng} \mathrm{mL}^{-1}$, respectively. These results indicate that the developed method is sensitive and repeatable. These results are very acceptable considering the complexity of the sample and the whole sample preparation procedure. The enrichment factor can be estimated as 100 from the ratio of the analyte concentration in the sedimented phase $\left(\mathrm{C}_{\text {sed }}\right)$ to the initial concentration of analyte $\left(\mathrm{C}_{0}\right)$ according to equation 1 .

\section{Analysis of real samples}

The applicability and accuracy of the proposed method were evaluated using five food samples. The accuracy of an analytical method describes the closeness of mean test results obtained by the method to the true value (concentration) of the analyte. It is determined by replicate analysis of samples containing known amounts of the analyte. Recovery studies were carried out in order to verify the accuracy of the proposed method by fortifying five samples (milk, milk powder, cheese, yogurt, and egg yolk) in triplicate at two concentration levels ( 5 and $40 \mathrm{ng} \mathrm{mL}^{-1}$ ). The results, along with the recovery for the spiked samples, are given in Table 2 .

Recovery values ranged between 97 and $102.8 \%$. This shows that the proposed procedure is qualified for the trace analysis of MEL from different food samples. The spectra obtained by CD-IMS for milk, milk powder, and cheese samples are shown in Figures S2a-c, respectively. The spectra show that due to the excellent sample clean-up capability of this method, the matrix components of the samples do not interfere with the quantification process. The MEL extraction and determination results using the 
Table 2. Determination of melamine in spiked and unspiked milk, milk powder, cheese, yogurt and egg yolk by DLLME-CD-IMS ( $\mathrm{n}=3)$

\begin{tabular}{lccc}
\hline Sample & $\begin{array}{c}\text { Added / } \\
\left(\mathrm{ng} \mathrm{mL}^{-1}\right)\end{array}$ & $\begin{array}{c}\text { Found (RSD) } \\
\left(\mathrm{ng} \mathrm{mL}^{-1}\right)\end{array}$ & Recovery / \% \\
\hline \multirow{3}{*}{ Milk } & - & $22.7(3.0)$ & - \\
& 5.0 & $27.8(3.1)$ & 102.8 \\
& 40.0 & $61.9(2.4)$ & 98.1 \\
\hline \multirow{3}{*}{ Milk powder } & - & $16.6(2.7)$ & - \\
& 5.0 & $21.6(2.4)$ & 98.8 \\
& 40.0 & $56.9(1.6)$ & 100.7 \\
\hline \multirow{4}{*}{ Cheese } & - & $8.3(3.4)$ & - \\
& 5.0 & $13.3(3.9)$ & 101.0 \\
& 40.0 & $49.4(3.4)$ & 102.7 \\
\hline \multirow{4}{*}{ Yogurt } & - & $5.1(3.2)$ & - \\
& 5.0 & $9.9(2.9)$ & 97.0 \\
& 40.0 & $43.9(2.8)$ & 97.0 \\
\hline \multirow{4}{*}{ Egg yolk } & - & $14.27(2.50)$ & - \\
& 5.0 & $19.28(2.33)$ & 100.2 \\
& 40.0 & $55.97(1.82)$ & 104.25 \\
\hline
\end{tabular}

aRSD: relative standard deviation.

proposed method were compared with the results obtained by HPLC-UV. As can be seen, the results obtained by the proposed method (Table 3) are in good agreement with those obtained by HPLC-UV. The HPLC-UV chromatograms for the standard and unspiked real samples are presented in Figures S3a-d.

\section{Comparison of DLLME-CD-IMS with other sample preparation techniques for determination of melamine}

Some different methods have been developed for the detection of melamine. The extraction efficiency of the
Table 3. Analytical results of melamine analysis in milk, milk powder, cheese, yogurt and egg yolk samples by DLLME-CD-IMS method and comparing with the obtained results using HPLC-UV method

\begin{tabular}{|c|c|c|}
\hline Sample & $\begin{array}{l}\text { Melamine found } \\
\text { (DLLME-CD-IMS } \\
\text { method) / }\left(\mu \mathrm{g} \mathrm{g}^{-1}\right)\end{array}$ & $\begin{array}{l}\text { Melamine found } \\
\quad\left(H P L C-U V^{c}\right. \\
\text { method) } /\left(\mu g^{-1}\right)\end{array}$ \\
\hline Milk powder & $0.166 \pm 0.006$ & $0.165 \pm 0.004$ \\
\hline Yogurt & $0.0511 \pm 0.002$ & $0.045 \pm 0.003$ \\
\hline Milk & $0.143 \pm 0.005$ & $0.146 \pm 0.003$ \\
\hline Cheese & $0.042 \pm 0.002$ & $0.039 \pm 0.003$ \\
\hline Egg yolk & $0.049 \pm 0.003$ & $0.05 \pm 0.004$ \\
\hline
\end{tabular}

${ }^{\mathrm{a}}$ Mean \pm standard deviation $\left(\mathrm{n}=3\right.$ ); ${ }^{\mathrm{b}}$ DLLME-CD-IMS: dispersive liquidliquid microextraction-corona discharge-ion mobility spectrometry; 'HPLC-UV: high-performance liquid chromatography with UV-Vis detector.

presented DLLME-CD-IMS method was compared with other reported methods from the viewpoint of linear range, LOD, time of extraction and RSD. Comparison results of the proposed method with different existing methods for extraction and determination of melamine is provided in Table 4 . These results show that the proposed method has a high sensitivity, linear range and very good precision with short extraction time. Thus, in the present method, inexpensive DLLME-IMS has the potential to achieve cleanup and enrichment of melamine in different food samples in a manner that is more effective than those of the other reported microextraction approaches (based on SPME, SDME, and polymer monolith microextraction).

Table 4. Comparison linear range, limit of detection (LOD), time and precision (RSD \%), for the analysis of melamine in different samples using proposed and other methods

\begin{tabular}{|c|c|c|c|c|c|c|}
\hline Method & Sample type & $\mathrm{LR}^{\mathrm{a}} /\left(\mathrm{ng} \mathrm{mL} L^{-1}\right)$ & $\begin{array}{l}\text { Limit of detection } \\
\text { (LOD) / }\left(\mathrm{ng} \mathrm{mL}^{-1}\right)\end{array}$ & time / min & $\begin{array}{c}\text { Relative standard } \\
\text { deviation (RSD) / \% }\end{array}$ & Reference \\
\hline EM-LPME-HPLC ${ }^{\mathrm{b}}$ & $\begin{array}{l}\text { infant milk powder, } \\
\text { bovine milk }\end{array}$ & $16-8000$ & $2-5.8$ & 15 & $3.9-6.6$ & 42 \\
\hline FAIMS-SPE ${ }^{c}$ & milk and dairy products & $0.3-25\left(\mathrm{mgL}^{-1}\right)$ & $0.1\left(\mathrm{mg} \mathrm{kg}^{-1}\right)$ & $\mathrm{IS}^{\mathrm{d}}<3$ & $<8$ & 16 \\
\hline Zr-HF-GC-MS ${ }^{e}$ & dairy products & $0.001-1000\left(\mu \mathrm{g} \mathrm{ml}^{-1}\right)$ & $0.001\left(\mu \mathrm{g} \mathrm{mL}^{-1}\right)$ & 150 & 5.9 & 43 \\
\hline SE-HF-LPME ${ }^{\mathrm{f}}$ & soil samples & $0.01-8\left(\mu \mathrm{g} \mathrm{mL}^{-1}\right)$ & $0.005\left(\mu \mathrm{g} \mathrm{mL} L^{-1}\right)$ & 60 & 4.0 & 44 \\
\hline MIPs-SERS ${ }^{g}$ & milk & $0.005-0.05\left(\mathrm{mmol} \mathrm{L}^{-1}\right)$ & $0.012\left(\mathrm{mmol} \mathrm{L}^{-1}\right)$ & 18 & - & 45 \\
\hline DSPE-LC-ES-MS/MS ${ }^{\mathrm{h}}$ & soil and strawberry & $5-500\left(\mu \mathrm{kg}^{-1}\right)$ & $0.2-1.3\left(\mu \mathrm{g} \mathrm{kg}^{-1}\right)$ & - & $3.5-9.6$ & 46 \\
\hline MIP-SB ${ }^{i}$ & powdered milk & $0.0631-12.6$ & 0.0127 & 90 & 5.3 & 47 \\
\hline DLLME-CD-IMS & $\begin{array}{l}\text { milk, milk powder, } \\
\text { yogurt, cheese, egg }\end{array}$ & $\begin{array}{c}0.5-70 \\
70-1500\end{array}$ & 0.25 & $\mathrm{IS}_{\mathrm{d}}<12$ & $<3.9$ & this work \\
\hline
\end{tabular}

${ }^{\mathrm{a} L R}$ : linear range; ${ }^{\mathrm{b} E M-L P M E-H P L C}$ : electromembrane-liquid phase microextraction-high performance liquid chromatography; ${ }^{\mathrm{F}} \mathrm{FAIMS}-\mathrm{SPE}$ : field

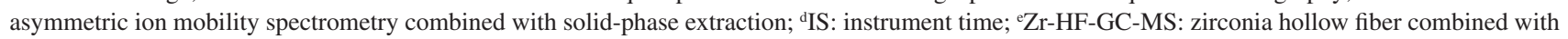

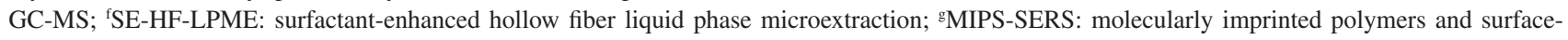
enhanced Raman spectroscopy; ${ }^{\mathrm{h} D S P E-L C-E S-M S / M S}$ : dispersive solid phase extraction liquid chromatography-electrospray tandem mass spectrometry; ${ }^{i}$ MIP-SB: molecularly imprinted stir bar. 


\section{Conclusions}

This work has demonstrated that the combination of DLLME with ion mobility spectrometry provides a novel route for extraction and determination of melamine. The main benefits of the DLLME method are: minimum use of toxic organic solvent, simplicity, low cost and enhancement of sensitivity. The analysis time in the proposed method was much shorter compared with the time required in the methods such as LC, GC or CE, thus both the extraction and detection of a sample taking about $30 \mathrm{~min}$. Furthermore, the reliability of this new method was equally acceptable. In addition to portability, IMS is much easier to use and is cost-effective compared to the other method. The results which were obtained in this study reveal the benefits of rapidity, sensitivity and convenience associated with DLLME-CD-IMS in real sample analysis. Various real samples were analyzed, without any derivatization process or powerful separation technique. The DLLME-CD-IMS method was exhaustively validated in terms of sensitivity, dynamic range and enrichment factor, the results demonstrated that the proposed method has great potential as a powerful tool for food analysis and safety inspection.

\section{Supplementary Information}

Supplementary information (containing the ion mobility spectrum of melamine in comparison with background spectrum, the spectra obtained by CD-IMS for milk, milk powder, and cheese samples, also the HPLC-UV chromatograms for the standard and unspiked real samples) are available free of charge at http://jbcs.sbq.org.br as PDF file.

\section{Acknowledgments}

The authors greatly appreciate the financial support of this work by Shahid Chamran University Research Council.

\section{References}

1. Rovina, K.; Siddiquee, S.; Wong, N. K.; Sensing and BioSensing Research 2015, 4, 16.

2. Puschner, B.; Poppenga, R. H.; Lowenstine, L. J.; Filigenzi, M. S.; Pesavento, P. A.; J. Vet. Diagn. Invest. 2007, 19, 616.

3. Yokley, R. A.; Mayer, L. C.; Rezaaiyan, R.; Manuli, M. E.; Cheung, M. W.; J. Agric. Food Chem. 2000, 48, 3352.

4. Batista, A. D.; Nascimento, C. F.; Melchert, W. R.; Rocha, F. R. P.; Microchem. J. 2014, 117, 106.

5. Jawaid, S.; Talpur, F. N.; Afridi, H. I.; Nizamani, S. M.; Khaskheli, A. A.; Naz, S.; Anal. Methods 2014, 6, 5269.
6. Sivashanmugan, K.; Liao, J. D.; Liua, B. H.; Yao, C. K.; Anal. Chim. Acta 2013, 800, 56.

7. Jawaid, S.; Talpur, F. N.; Sherazi, S. T. H.; Nizamani, S. M.; Khaskheli, A. A.; Food Chem. 2013, 141, 3066.

8. Zhou, Y.; Li, C. Y.; Li, Y. S.; Ren, H. L.; Lu, Sh. Y.; Tian, X. L.; Hao, Y. M.; Zhang, Y. Y.; Shen, Q. F.; Liu, Z. Sh.; Meng, X. M.; Zhang, J. H.; Food Chem. 2012, 135, 2681.

9. Lutter, P.; Savoy-Perroud, M. C.; Campos-Gimenez, E.; Meyer, L.; Goldmann, T.; Bertholet, M. C.; Mottier, P.; Desmarchelier, A.; Monard, F.; Perrin, C.; Robert, F.; Delatour, T.; Food Control 2011, 22, 903.

10. Tkachenko, A.; Clark, J.; Knutson, N.; Wallace, B.; Bomba, M.; Yacopucci, M.; Rhodes, B.; Nemser, S. M.; Guag, J.; Reimschuessel, R.; Food Chem. Toxicol. 2015, 8, 310.

11. Tzing, S. H.; Ding, W. H.; J. Chromatogr. A 2010, 1217, 6267.

12. Kailasa, S. K.; Wu, H. F.; J. Ind. Eng. Chem. 2015, 21, 138.

13. Ibenez, M.; Sancho, J. V.; Hernandez, F.; Anal. Chim. Acta 2009, 649, 91.

14. Fashi, A.; Yaftian, M. R.; Zamani, A.; Food Chem. 2015, 188, 92.

15. Squadrone, S.; Ferro, G. L.; Marchis, D.; Mauro, C.; Palmegiano, P.; Amato, G.; Poma Genin, E.; Abete, M. C.; Food Control 2010, 21, 714.

16. Zhao, W.; Wang, Y.; Li, J.; Li, L.; Wang, Q.; Han, K.; Zhang, Y.; Li, X.; Li, P.; Luo, J.; Wang, X.; Food Chem. 2015, 188, 489.

17. Pan, X. D.; Wu, P.; Yang, D. J.; Wang, L.Y.; Shen, X. H.; Zhu, C. Y.; Food Control 2013, 30, 545.

18. Liu, B.; Xiao, B.; Cui, L.; Wang, M.; Mater. Sci. Eng., C 2015 , 55,457

19. Wu, H.; Li, H.; Chua, F. Z. H.; Li, S. F. Y.; Sens. Actuators, $B$ 2013, 178, 541.

20. Guo, H.; Zhou, X.; Zhang, Y.; Song, B.; Liu, L.; Zhang, J.; Shi, H.; Sens. Actuators, B 2014, 194, 114.

21. Behbahani, M.; Najafi, F.; Bagheri, S.; Kalate Bojdi, M.; Salarian, M.; Bagheri, A.; J. Chromatogr. A 2013, 1308, 25.

22 Rezaee, M.; Assadi, Y.; Hosseini, M. R. M.; Aghaee, E.; Ahmadi, F.; Berijani, S.; J. Chromatogr. A 2006, 1116, 1.

23. Lana, N. B.; Berton, P.; Covaci, A.; Atencio, A. G.; Ciocco, N. F.; Altamirano, J. C.; J. Chromatogr. A 2013, 1285, 15.

24. Suha, J. H.; Lee, Y. Y.; Lee, H. J.; Kang, M.; Hur, Y.; Lee, S. N.; Yang, D. H.; Han, S. B.; J. Pharm. Biomed. Anal. 2013, 75, 214.

25. Campillo, N.; Vinas, P.; Melgarejo, G. F.; Cordoba, M. H.; J. Chromatogr. A 2013, 1282, 20.

26. Jafari, M. T.; Riahi, F.; J. Chromatogr. A 2014, 1343, 63.

27. Vinas, P.; Bravo, M. B.; García, I. L.; Cordoba, M. H.; Talanta 2013, 115, 806.

28. Andruch, V.; Kocurova, L.; Balogh, I. S.; Skrlıkova, J.; Microchem. J. 2012, 102, 1.

29. Ho, Y. M.; Tsoi, Y. K.; Leung, K. S.Y.; Anal. Chim. Acta 2013 , $775,58$. 
30. Al-Saidi, H. M.; Emara, Adel, A. A.; J. Saudi Chem. Soc. 2014, 18,745 .

31. Armenta, S.; de la Guardia, M.; Alcalà, M.; Blanco, M.; PerezAlfonso, C.; Galipienso, N.; Talanta 2014, 130, 251.

32. Jafari, M. T.; Badihi, Z.; Jazan, E.; Talanta 2012, 99, 520.

33. Tabrizchi, M.; ILbeigi, V.; J. Hazard. Mater. 2010, 176, 692.

34. Tabrizchi, M.; Khayamian, T.; Rev. Sci. Instrum. 2000, 71, 2321.

35. Daneshfar, A.; Khezeli, T.; Lotfi, H. J.; J. Chromatogr. B 2009, 877, 456.

36. Filazi, A.; Sireli, U. T.; Ekici, H.; Can, H. Y.; Karagoz, A.; J. Dairy Sci. 2012, 95, 602.

37. Nagaraju, D.; Huang, S. D.; J. Chromatogr. A 2007, 1161, 89.

38. Borsdorf, H.; Eiceman, G. A.; Appl. Spectrosc. Rev. 2006, 41, 323.

39. Stach, J.; Baumbach, J. I.; Int. J. Ion Mobility Spectrom. 2002, 5,1 .

40. Liu, Y.; Deng, J.; An, L.; Liang, J.; Chen, F.; Wang, H.; Food Chem. 2011, 126, 745.
41. Miller, J. C.; Miller, J. N.; Statistics and Chemometrics for Analytical Chemistry, 6 ${ }^{\text {th }}$ ed.; Prentice Hall: UK, 2010.

42. Fashi, A.; Yaftian, M. R.; Zamani, A.; Food Chem. 2015, 188, 92.

43. Li, J.; Qi, H. Y.; Shi, Y. P.; J. Chromatogr. A 2009, 1216, 5467.

44. Yazdi, A. S.; Yazdinezhad, S. R.; Heidari, T.; J. Adv. Res., in press, DOI:10.1016/j.jare.2014.10.010.

45. Hu, Y.; Feng, S.; Gao, F.; Li-Chan, E. C.; Grant, E.; Lu, X.; Food Chem. 2015, 176, 123.

46. Ge, J.; Zhao, L. W.; Liu, C. Y.; Jiang, S.; Lee, P. W.; Liu, F.; Food Control 2011, 22, 1629.

47. Zhu, L.; Xu, G.; Wei, F.; Yang, J.; Hu, Q.; J. Colloid Interface Sci. 2015, 454, 8 .

Submitted: November 5, 2015 Published online: February 12, 2016 